\title{
Effect of Air/Biomass Ratio on the Gasification of Olive Bagasse Particles
}

\author{
Ana F. Almeida, Mónica S. Vieira, Albina M. Ribeiro, Isabel. M. Pereira, Maria P. Neto, and Rosa M. \\ Pilão
}

\begin{abstract}
In this experimental study the evolution of gas characteristics during the gasification of olive bagasse particles was investigated using a semi-batch fluidized-bed gasifier. Sand particles with a mean diameter of $375 \mu \mathrm{m}$ were used as bed material and an air flow was used as the fluidizing agent. Experimental tests were conducted with particles of diameter ranging from in 1.25 to $2 \mathrm{~mm}$. The material was characterised through elemental and proximate analysis, and the higher heating value was also measured. In each run, the major components of the gas phase were identified as $\mathrm{CO}, \mathrm{CO}_{2}, \mathrm{H}_{2}$, $\mathrm{CH}_{4}, \mathrm{O}_{2}$ and $\mathrm{N}_{2}$. Gaseous samples were collected and analysed by gas chromatography (Dani 1000 DPC). The effect of air/biomass ratio on gasification performance was studied. The tests were conducted at three different air flow rates and the load of biomass was also changed. The results show that the of air flow increases the $\mathrm{H}_{2}, \mathrm{CO}$ and $\mathrm{CH}_{4}$ content in the producer gas. Results also show an increase in the dry gas yield, carbon conversion and the gas heating values as air flow rate decreases. Findings reveal as well that the increase of biomass load reduces the composition in $\mathrm{H}_{2} \mathrm{CO}$ and $\mathrm{CH}_{4}$ of the producer gas, leading to the decrease of the gasification performance parameters.
\end{abstract}

Index Terms - Gasification, olive bagasse particles, producer gas, semi-batch fluidized bed.

\section{INTRODUCTION}

Gasification processes provide the opportunity to convert renewable biomass feedstock into clean fuel gases.

Gasification is the conversion of the biomass into a combustible gas mixture through its partial oxidation at high temperature, usually in the range of 800 to $900^{\circ} \mathrm{C}$. In most cases, solid char plus tars that would be liquids under ambient conditions are also formed. The gasification process generally involves pyrolysis as well as combustion. Combustion provides heat for the endothermic pyrolysis reactions. The resulting gas, known as producer gas, mainly contains carbon monoxide, hydrogen, and methane along with carbon dioxide and nitrogen [1].

The four major gasification reactions are the following [2] with corresponding reaction heat values:

Water-gas reaction: $\mathrm{C}+\mathrm{H}_{2} \mathrm{O} \leftrightarrow \mathrm{H}_{2}+\mathrm{CO}-131.38 \mathrm{~kJ} / \mathrm{mol}$

Boudouard reaction: $\mathrm{CO}_{2}+\mathrm{C} \leftrightarrow 2 \mathrm{CO}-172.58 \mathrm{~kJ} / \mathrm{mol}$

Shift conversion: $\mathrm{CO}+\mathrm{H}_{2} \mathrm{O} \leftrightarrow \mathrm{CO}_{2}+\mathrm{H}_{2}-41.98 \mathrm{~kJ} / \mathrm{mol}$

Methanation: $\mathrm{C}+2 \mathrm{H}_{2} \leftrightarrow \mathrm{CH}_{4}+74.9 \mathrm{~kJ} / \mathrm{mol}$

To assess the gasification performance, the following four parameters [2]-[4] were defined:

1) Carbon conversion efficiency $(\%)$ :

Manuscript received March 20, 2015; revised June 16, 2015.

The authors are with the CIETI, Instituto Superior de Engenharia do Porto, IPP, Rua Dr. António Bernardino de Almeida 431, 4200-072 Porto, Portugal (e-mail: afdsa@isep.ipp.pt, msmve@isep.ipp.pt, asr@isep.ipp.pt, imp@isep.ipp.pt,mpp@isep.ipp.pt,rmp@isep.ipp.pt).

$$
\eta_{c}=\frac{12 \times A}{\% C \times m_{c}} \times 100
$$

where $A$ is the total number of moles of carbon-bearing components $\left(\mathrm{CO}_{2}, \mathrm{CO}\right.$ and $\left.\mathrm{CH}_{4}\right)$ present in the producer gas during gasification time, $\mathrm{m}_{\mathrm{c}}$ is the mass of biomass fed to the reactor $(\mathrm{kg})$ and $\% \mathrm{C}$ is the carbon content in the ultimate analysis of biomass.

2) Dry gas yield $\left(\mathrm{Nm}^{3} / \mathrm{kg}\right)$ :

$$
Y=\frac{V_{g}}{(1-\% h) \times m_{c}}
$$

where $V_{g}$ is the total volume $\left(\mathrm{Nm}^{3}\right)$ of gas produced during gasification calculated from the nitrogen balance, considering that nitrogen in biomass is negligible $(\% \mathrm{~h}$ is the biomass moisture).

3) Cold gas efficiency (\%):

$$
\eta_{g}=\frac{V_{g} \times H H V_{g}}{m_{c} \times H H V_{c}} \times 100
$$

where $H H V_{c}$ is the biomass higher heating value $(\mathrm{kJ} / \mathrm{kg})$ and $H H V_{g}$ is the higher heating value $\left(\mathrm{kJ} / \mathrm{Nm}^{3}\right)$ of the producer gas.

4) Dry producer gas high heating value $\left(\mathrm{kJ} / \mathrm{Nm}^{3}\right)$ :

$$
\begin{aligned}
& H H V_{g}=\left(\% \mathrm{H}_{2} \times 30.52+\% \mathrm{CO} \times 30.18+\% \mathrm{CH}_{4} \times\right. \\
& 95 \times 4.2
\end{aligned}
$$

where $\% \mathrm{H}_{2}, \% \mathrm{CO}$ and $\% \mathrm{CH}_{4}$ are the average calculated volumetric concentrations in the total producer gas during the gasification process.

The aim of this work is to present the preliminary results of the study on air gasification of olive bagasse particles, using a semi-batch fluidized bed reactor. The influence of air/biomass ratio was studied at $850^{\circ} \mathrm{C}$.

\section{MATERIALS AND METHODS}

\section{A. Feed/Raw Material}

Olive bagasse particles with particle size ranging from 1.25 to $2 \mathrm{~mm}$ were used as biomass feedstock for performing the experiments. The proximate and ultimate analyses are reported in Table I.

The high level of volatile content is an indication of the raw material's ability to be used in gasification processes.

High moisture content in the olive bagasse particles may negatively affect the energy balance and the producer gas composition. However, a small amount of it in the biomass improves the reforming reactions, especially at high 
temperatures due to the endothermic nature of these reactions [5].

\section{Methane steam reforming:}

$$
\begin{gathered}
\mathrm{CH}_{4}+\mathrm{H}_{2} \mathrm{O} \leftrightarrow \mathrm{CO}+3 \mathrm{H}_{2}-206 \mathrm{~kJ} / \mathrm{mol} \\
\mathrm{CH}_{4}+2 \mathrm{H}_{2} \mathrm{O} \leftrightarrow 4 \mathrm{H}_{2}+\mathrm{CO}_{2}-165 \mathrm{~kJ} / \mathrm{mol}
\end{gathered}
$$

Considering these results, olive bagasse particles show good characteristics allowing them be used as raw material in biomass gasification processes.

TABLE I: Proximate AND Ultimate ANALyses of Olive Bagasse

\begin{tabular}{ll}
\multicolumn{2}{c}{ PARTICLES } \\
\hline Moisture $(\mathrm{w} / \mathrm{w} \%)$ & 8.7 \\
$\mathrm{HHV}_{\mathrm{c}}{ }^{(1)}(\mathrm{kJ} / \mathrm{kg}$ a.r $)$ & 20830
\end{tabular}

\begin{tabular}{ll} 
Proximate analysis $(w \boldsymbol{t} / \boldsymbol{w} \%$ a.r $)$ & \\
Volatiles & 84.0 \\
Fixed carbon & 3.9 \\
Asch & 3.4 \\
Ultimate analysis $(\boldsymbol{w} / \boldsymbol{w} \%$ a.r $)$ & \\
Carbon & 52.5 \\
Hydrogen & 7.3 \\
Nitrogen & 1.5 \\
Oxygen, diff. & 30.0 \\
\hline
\end{tabular}

\section{B. Experimental Set-up}

The reactor (Fig. 1) is made of stainless steel tube with an internal diameter of $54 \mathrm{~mm}$ and a height of $800 \mathrm{~mm}$. The reactor is surrounded by a $3 \mathrm{~kW}$ electrical resistance which allows the temperature to be raised to the desired level. The gas distributor, at the bottom of the fluidizing column, is a uniformly perforated plate with $0.6 \mathrm{~mm}$ diameter holes.

Sand particles with diameters in the range of $250 \mu \mathrm{m}$ to $500 \mu \mathrm{m}$ were used as bed material. Air was used as a fluidising agent and gas flow was measured with a rotameter. The reactor was equipped with an external condenser and a cyclone. A thermocouple and a pressure probe were used to monitor the fluidising conditions in the reactor.

\section{Experimental Procedure}

Air was fed into the reactor at the desired fixed flow rate.
The bed material was preheated to $850^{\circ} \mathrm{C}$ before the biomass batch load was fed in, using a pipe ending near the bed surface.

During the gasification process, several samples of dry and clean gas were taken and analysed in a gas chromatograph (Dani 1000 DPC). The GC is fitted with an OPT333 injector suitable for packed columns and a thermal conductivity detector (TCD OPT266). A 60/80 Carboxen 1000 column was used with argon as carrier gas.

The gases detected and quantified in the gasification process were $\mathrm{H}_{2}, \mathrm{O}_{2}, \mathrm{~N}_{2}, \mathrm{CO}, \mathrm{CH}_{4}$ and $\mathrm{CO}_{2}$.

\section{EFFECT OF FLOW RATE}

The effect of air flow rate on gasification performance was studied by performing tests at $850{ }^{\circ} \mathrm{C}$ and using $5 \mathrm{~g}$ of biomass. The tests were conducted at three different air flow rates: $0.36 \mathrm{~kg} / \mathrm{h}, 0.25 \mathrm{~kg} / \mathrm{h}$ and $0.17 \mathrm{~kg} / \mathrm{h}$.

In gas-solid systems, increasing the gas flow above the incipient fluidization leads to the formation of bubbles which ascend through the bed and which result from excess gas. This behaviour results in the transport of particles to the bed surface and the emergence of preferential paths for the gas flow.

For the average diameter of the bed particles used $(375 \mu \mathrm{m})$ and the three air flow rates tested, the values observed for the ratio between gas surface velocity $\left(v_{0}\right)$ and minimum velocity for fluidization $\left(v_{m f}\right)$ were $1,1.4$ and 2 .

There are several studies regarding the type of regime in a fluidized bed against the operating conditions. Wen-Ching [5] presents maps of fluidized beds which limited the type of bed regimes depending on two dimensionless parameters. In the tested conditions, according to Wen-Ching, the bed is in the incipient fluidized regime for the flow rate of $0.17 \mathrm{~kg} / \mathrm{h}$ and in the fluidized regime for the two other flow rates.

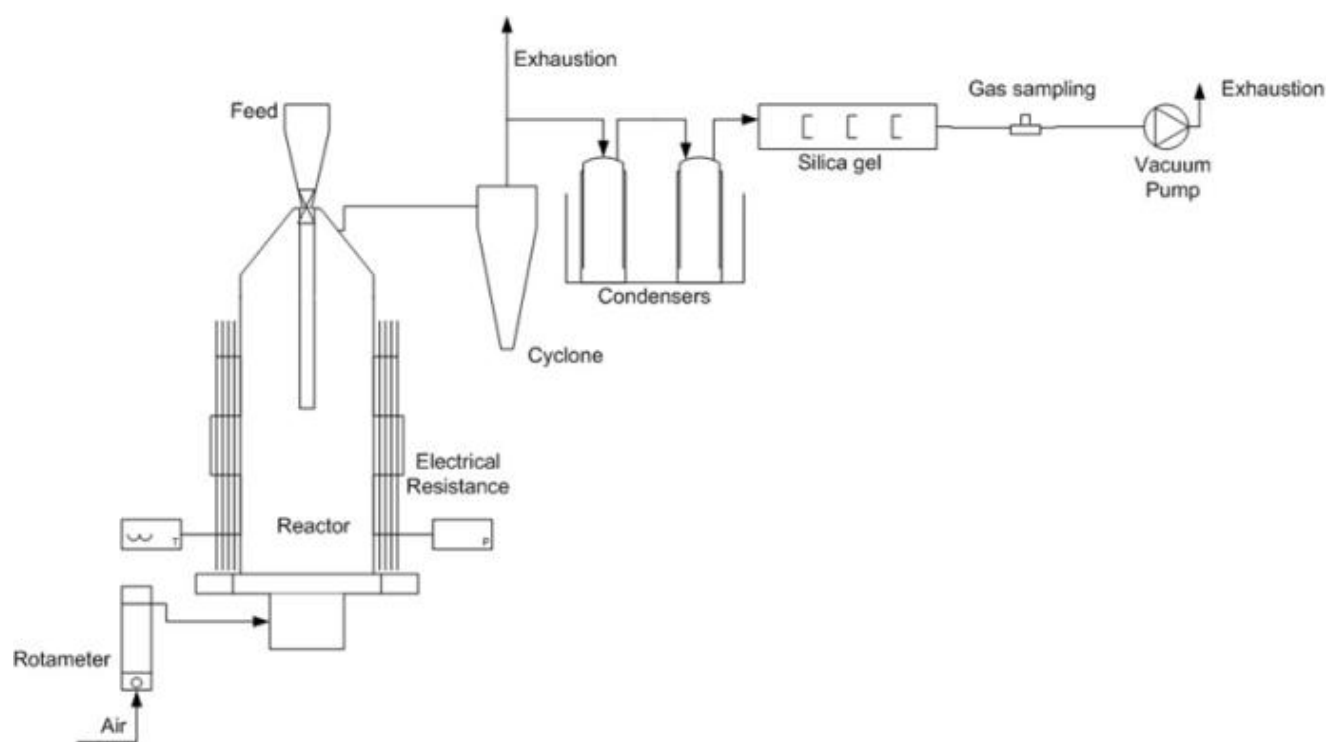

Fig. 1. Experimental configuration.

The results obtained concerning the evolution of $\mathrm{H}_{2}, \mathrm{CO}$ and $\mathrm{CH}_{4}$ during the gasification process are shown in Fig. 2.

The results show that decreasing the air flow rate favours the content increase in $\mathrm{H}_{2}, \mathrm{CO}$ and $\mathrm{CH}_{4}$ in producer gas.
In fact, the reduction of air flow rate for the same load of biomass leads to the reduction of initial air/biomass ratio (A/C) and also to the reduction of $\mathrm{v}_{0} / \mathrm{v}_{\mathrm{mf}}$ (longer residence time of producer gas in the reactor). Therefore, tests were 
performed with different bed hydrodynamic fluidization regimes.
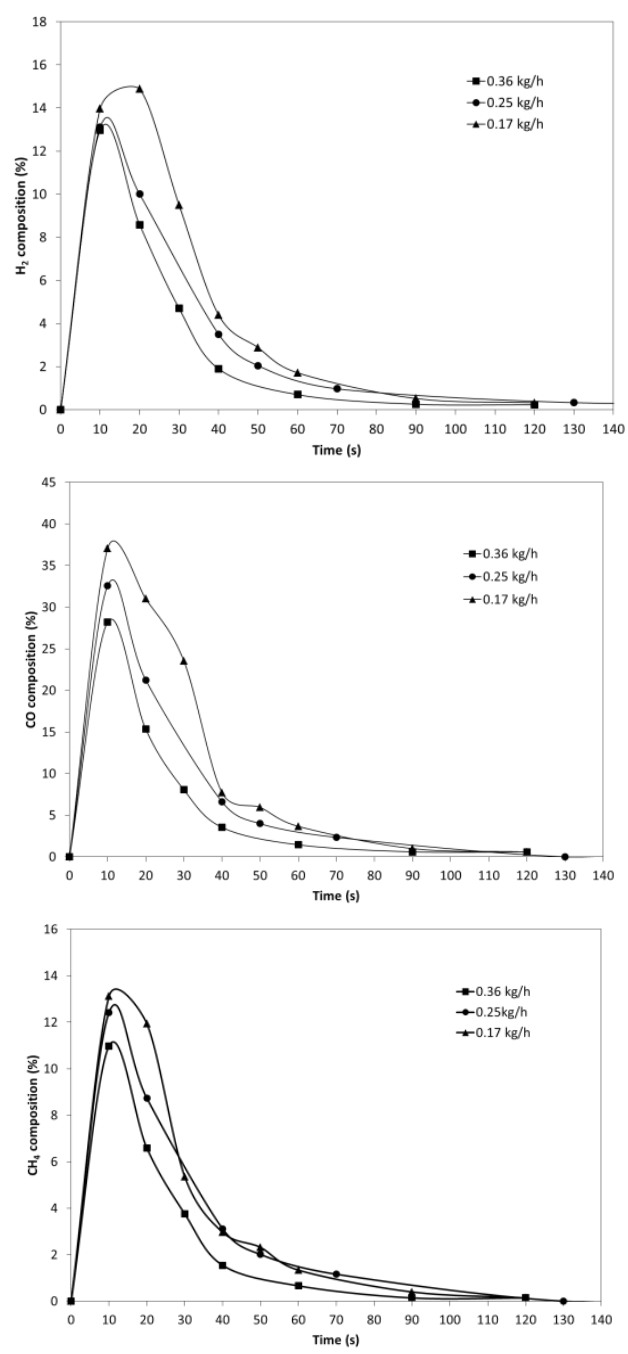

Fig. 2. Flow rate effect on $\mathrm{H}_{2}, \mathrm{CO}$ e $\mathrm{CH}_{4}$ production.

It seems that, for a semi-batch system, a low hydrodynamic regime favours the gasification performance.

Fig. 3 summaries the influence of the air flow rate on the average composition of the producer gas. These compositions were estimated through the integration of composition vs. time evolution curves.

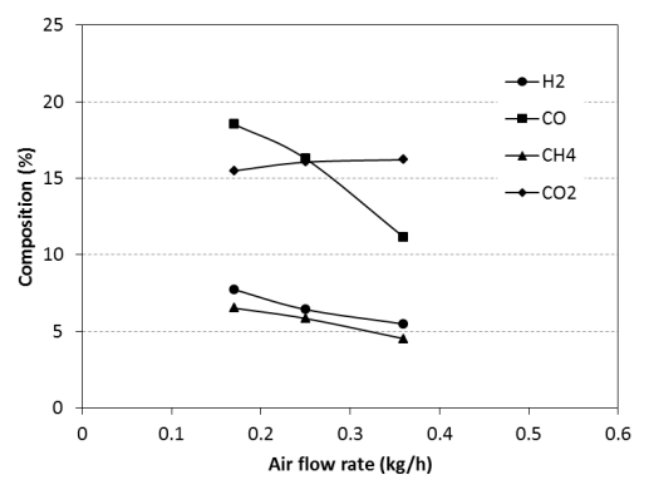

Fig. 3. Effect of flow rate on average producer gas composition.

The results obtained for the performance of gasification are shown in Table II. These results reveal that the decrease in air flow rate results in the improvement of all performance assessment parameters, with slight differences for the two lowest air flow rates tested.
As expected, the maximum $\mathrm{HHV}_{\mathrm{g}}$ of $5.9 \mathrm{MJ} / \mathrm{Nm}^{3}$ was obtained with the lower air/biomass ratio, which corresponds to the producer gas with a higher content of combustible gases (Fig. 3). Maximum values of carbon conversion efficiency, cold gas efficiency and dry gas yield were $63.1 \%$ and $43.4 \%$ and $1.7 \mathrm{Nm}^{3} / \mathrm{kg}$, respectively.

TABLE II: GASIFICATION PERFORMANCE PARAMETERS

\begin{tabular}{|lccc|}
\hline Flow rate $(\mathbf{k g} / \mathbf{h})$ & $\mathbf{0 . 3 6}$ & $\mathbf{0 . 2 5}$ & $\mathbf{0 . 1 7}$ \\
\hline $\mathrm{v}_{0} / \mathrm{v}_{\mathrm{mf}}$ & 2 & 1.4 & 1 \\
$(\mathrm{~A} / \mathrm{C})$ ratio $(\mathrm{kg}$ air/kg biomass) & 1.80 & 1.25 & 1.13 \\
\hline Carbon conversion efficiency $(\boldsymbol{\%})$ & 62.6 & 62.0 & 63.1 \\
Dry gas yield $\left(\mathbf{N m}^{\mathbf{3}} / \mathbf{k g}\right)$ & 2.11 & 1.75 & 1.67 \\
Cold gas efficiency $(\boldsymbol{\%})^{\mathbf{3}}$ & 36.2 & 39.9 & 43.4 \\
$\mathbf{H H V}_{\mathbf{g}}\left(\mathbf{M J} / \mathbf{N m}^{\mathbf{3}}\right)$ & 3.9 & 5.2 & 5.9 \\
\hline
\end{tabular}

\section{EFFECT OF BIOMASS LOAD}

The effect of increasing biomass gasification load was evaluated by performing tests with constant air flow rate, while biomass weight was changed in the range of $3 \mathrm{~g}$ to $7 \mathrm{~g}$. Tests were performed with $0.25 \mathrm{~kg} / \mathrm{h}$ and $0.17 \mathrm{~kg} / \mathrm{h}$ in order to detect the small differences obtained in the gasification performance parameters for these two air flow rates (Table II).

Under these conditions, tests at same flow rate were conducted under the same bed hydrodynamic regime and with different initial $(\mathrm{A} / \mathrm{C})$ ratios.

Increasing the biomass load from $5 \mathrm{~g}$ to $7 \mathrm{~g}$, does not result in better gasification performance. Instead it shows a reduction of all gasification parameters (Table III and Table IV). The reduction of the biomass load to $3 \mathrm{~g}$ seems to improve the gasification performance. This behaviour is more evident in the results obtained with an air flow rate of $0.25 \mathrm{~kg} / \mathrm{h}$.

The lowest dependency on the reduction of mass load observed with air flow rate of $0.17 \mathrm{~kg} / \mathrm{h}$ can be related to the fact that, for this flow rate, the working conditions are closer to the incipient fluidization regime.

The best results were obtained with a flow rate of 0.25 $\mathrm{kg} / \mathrm{h}$ and $3 \mathrm{~g}$ of biomass. Values of $70.6 \%$ and $56.2 \%$ were obtained for carbon conversion efficiency and cold gas efficiency. For dry gas yield the value of $1.9 \mathrm{Nm}^{3} / \mathrm{kg}$ was obtained and the $\mathrm{HHV}_{\mathrm{g}}$ of the producer gas was $5.8 \mathrm{MJ} / \mathrm{Nm}^{3}$.

TABLE III: GASIFICATION PARAMETERS FOR $\mathrm{V}_{0} / \mathrm{V}_{\mathrm{MF}}$ RATIO OF 1.4
\begin{tabular}{|lccc|}
\hline Biomass $(\mathbf{g})$ & $\mathbf{3}$ & $\mathbf{5}$ & $\mathbf{7}$ \\
\hline Carbon conversion efficiency $(\boldsymbol{\%})$ & 70.6 & 62.0 & 59.5 \\
Dry gas yield $\left(\mathbf{N m}^{\mathbf{3}} / \mathbf{k g}\right)$ & 1.9 & 1.7 & 1.6 \\
Cold gas efficiency $(\boldsymbol{\%})^{\mathbf{3}}$ & 56.2 & 39.9 & 41.1 \\
HHV $_{\mathbf{g}}\left(\mathbf{M J} / \mathbf{N m}^{\mathbf{3}} \mathbf{b . s}\right)$ & 5.8 & 5.2 & 5.0 \\
\hline
\end{tabular}

TABLE IV: GASIFICATION PARAMETERS FOR $\mathrm{V}_{0} / \mathrm{V}_{\mathrm{MF}}$ RATIO OF 1
\begin{tabular}{|lccc|}
\hline Biomass $(\mathbf{g})$ & $\mathbf{3}$ & $\mathbf{5}$ & $\mathbf{7}$ \\
\hline Carbon conversion efficiency $(\boldsymbol{\%})$ & 53.9 & 63.1 & 59.1 \\
Dry gas yield $\left(\mathbf{N m}^{\mathbf{3}} / \mathbf{k g}\right)$ & 1.5 & 1.7 & 1.3 \\
Cold gas efficiency $(\boldsymbol{\%})^{\mathbf{3}}$ & 39.6 & 43.4 & 40.5 \\
HHV $_{\mathbf{g}}\left(\mathbf{M J} / \mathbf{N m}^{\mathbf{3}}\right)$ & 6.2 & 5.9 & 6.9 \\
\hline
\end{tabular}

The order of magnitude of the values obtained lies within the range of normal values for the biomass gasification compared to published values for continuous fluidized bed gasification [6], [7]. 
Fig. 4 shows the variation of average producer gas composition with respect to biomass feed. The results in Fig. 4 show that the $\mathrm{H}_{2}$ and $\mathrm{CH}_{4}$ content in the producer gas are not significantly altered by the increase in biomass loading. The CO content in the producer gas increases with the decrease in biomass loading.

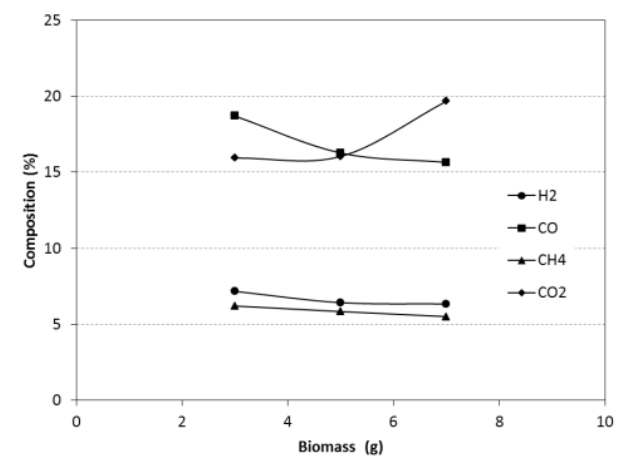

Fig. 4. Effect of biomass load on average producer gas composition for air flow rate of $0.25 \mathrm{~kg} / \mathrm{h}$.

\section{CONCLUSION}

The results obtained with olive bagasse show gasification performance values in the range of values published by other authors for different kind of biomass, especially when compared to the feedstock of the reference material for gasification: sawdust.

It is expected that, in continuous operating conditions where the richness of the air/biomass mixture remains constant throughout the process, the olive bagasse will improve the performance of the gasification process.

\section{REFERENCES}

[1] Taylor \& Francis Group, Handbook of Plant-based Biofuels, A. Pandey ed., New York, 2009.

[2] P. Basu, Combustion and Gasification in Fluidized Beds, Taylor \& Francis Group, 2006.

[3] K. Shayan, G. Regan, G. Rajender, and J. S. Raymond, "Study of factors affecting syngas quality and their interactions in fluidized bed gasification of lignite coal," Fuel, vol. 103, pp. 308-320, 2013.

[4] P. M. Lv, Z. H. Xiong, J. Chang, C. Z. Wu, Y. Chen, and J. X. Zhu, “An experimental study on biomass air-steam gasification in fluidized bed," Bioresource Technology, vol. 95, pp. 95-101, 2004.

[5] W.-C. Yang, Handbook of Fluidization and Fluid-Particle Systems, Marcel Dekker, Inc, NewYork. Basel, 2003.

[6] L. Pooya and A. Zainal, "Gasification of palm empty fruit bunch in a bubbling fluidized bed: A performance and agglomeration study," Bioresource Technology, vol. 102, pp. 2068-2076, 2011.

[7] M. Compoy, G. Alberto, O. Pedro, and N. Susanna, "Gasification of wastes in a pilot fluidized bed gasifier," Fuel Processing Technology, vol. 121, pp. 63-69, 2014.

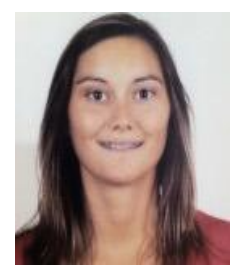

Ana Almeida was born in Azores, Portugal. She holds two degrees, one in biomedical laboratory science (2010) and one in chemical engineering (2013). Presently, she is attending the master's degree in chemical engineering, energetic optimization in the chemical industry. She has been a scientific researcher at CIETI since 2013. Her main research work has been dedicated to the study of biodiesel production from new raw materials and energetic valorisation of industria waste using gasification and pyrolysis reactors.

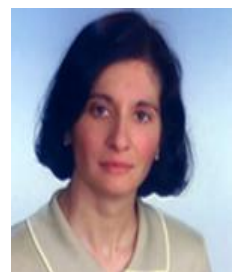

Albina Ribeiro was born in Oporto, Portugal. She completed her $\mathrm{PhD}$ in chemical engineering at University of Birmingham, UK, in 1994. She is a coordinator professor at the Department of Chemical Engineering of the Instituto Superior de Engenharia do Porto, Portugal. Her main research interests are related to the field of multiphase flow and heat transfer.

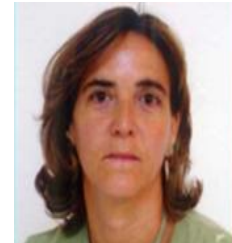

Paula Neto was born in Castelo de Paiva, Portugal. She completed her $\mathrm{PhD}$ in engineering sciences at University of Oporto, Portugal, in 2008 and holds a M.Sc in mechanical engineering, completed at University of Oporto, Portugal, in 1996. She is an adjunt professor at the Department of Chemical Engineering of the Instituto Superior de Engenharia do Porto, Portugal. Her main research interests are related to the field of fluidization and heat transfer.

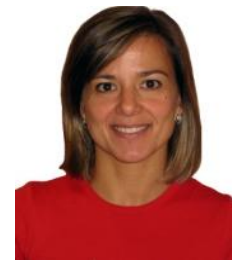

Rosa Pilão was born in Vila Pery, Mozambique. She completed her $\mathrm{PhD}$ in engineering sciences at University of Oporto, Portugal, in 2003 and holds a M.Sc in mechanical engineering from the University of Oporto, Portugal, completed in 1996. She is an adjunt professor at the Department of Chemical Engineering of the Instituto Superior de Engenharia do Porto, Portugal. Her main research interests are related to the field of dust explosions and combustion/gasification.

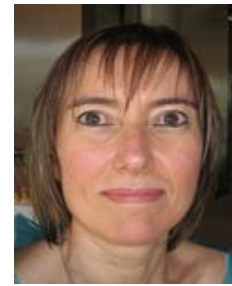

Isabel Pereira was born in Viseu, Portugal. She completed her $\mathrm{PhD}$ in chemical engineering at University of Oporto, Portugal in 1997. She is an adjunt professor at the Department of Chemical Engineering of the Instituto Superior de Engenharia do Porto, Portugal. Her main research interests are in the area of gaseous emissions and swimming pool water treatment.

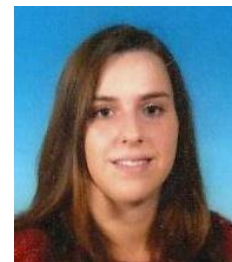

Mónica Vieira was born in Oporto, Portugal and holds a master's degree in chemical engineering, energetic optimization in the chemical industry. She has been a scientific researcher at CIETI since September 2014. Her main research work has been dedicated to the study of energetic valorisation of industrial waste using gasification and pyrolysis reactors. 